\title{
Indexical Relativism?
}

\author{
Eduardo Pérez-Navarro ${ }^{1}$ (D)
}

Received: 15 September 2020 / Revised: 4 October 2021 / Accepted: 9 November 2021 / Published online: 23 November 2021

(c) The Author(s) 2021

\begin{abstract}
The particular behavior exhibited by sentences featuring predicates of personal taste such as "tasty" may drive us to claim that their truth depends on the context of assessment, as MacFarlane does. MacFarlane considers two ways in which the truth of a sentence can depend on the context of assessment. On the one hand, we can say that the sentence expresses a proposition whose truth-value depends on the context of assessment. This is MacFarlane's position, which he calls "truth relativism" and, following Weatherson, I rebrand as "nonindexical relativism". On the other hand, we can say that what proposition a sentence expresses depends on the context of assessment. MacFarlane calls this position "content relativism" and rejects it on the grounds that it leads to implausible readings of certain sentences and is unable to account for the speaker's authority over the content of her assertions. In this paper, I too argue against content relativism, which, again following Weatherson, I rebrand as "indexical relativism". However, my arguments against the theory are different from MacFarlane's, which I prove unsound. In particular, I show that any version of indexical relativism will be unable to account for at least one of the phenomena that have been standardly used to motivate nonindexical relativism-faultless disagreement and retraction - in most of the ways in which it has been proposed to understand them.
\end{abstract}

Keywords Predicates of personal taste $\cdot$ Relativism $\cdot$ Indexical relativism $\cdot$ Faultless disagreement $\cdot$ Retraction

\section{Introduction}

The particular behavior exhibited by sentences featuring predicates of personal taste such as "tasty" may drive us to claim that their truth depends on the context of assessment, as MacFarlane (2014) does. If this were so, a sentence such as

Eduardo Pérez-Navarro

edperez@ugr.es

1 Departamento de Filosofía I, Universidad de Granada, Granada, Spain 
(1) Licorice is tasty.

as used at context $c$ and assessed from context $c^{\prime}$, would only be true or false with respect to a personal taste standard that is not determined by $c$, but by $c^{\prime}$. MacFarlane considers two ways in which the truth of a sentence can depend on the context of assessment (MacFarlane 2014, pp. 72-76). On the one hand, we can say that the sentence expresses a proposition whose truth-value depends on the context of assessment. This is MacFarlane's position, which he calls "truth relativism" and, following Weatherson (2009), I will rebrand as "nonindexical relativism". On the other hand, we can say that what proposition a sentence expresses depends on the context of assessment. MacFarlane calls this position "content relativism" and rejects it on two grounds. First, he takes it to lead to implausible readings of sentences like

\section{(2) I asserted that licorice is pleasing to my tastes.}

according to which, by using such sentences, the speaker is saying that she asserted that licorice is pleasing to the assessor's tastes. He concedes that we can overcome this obstacle if we combine content relativism for (1) with truth relativism for (2), but claims that it is more parsimonious to apply the latter across the board. Second, MacFarlane considers content relativism unable to account for the speaker's authority over the content of her assertions, as she would have no right to deny that it is a particular assessor's tastes that she is talking about. In this paper, I too argue against content relativism, which, again following Weatherson, I rebrand as "indexical relativism". However, my arguments against the theory are different from MacFarlane's, which I find unsound. In particular, I show that any version of indexical relativism will be unable to account for at least one of the phenomena that have been standardly used to motivate nonindexical relativism-faultless disagreement and retraction-in most of the ways in which it has been proposed to understand them.

I carry out the aim of this paper in two steps. First, I explore what embracing indexical relativism commits us to, and do so by comparing it with other theories to which it looks superficially similar. This classificatory work will be useful inasmuch as it serves to convince us that we do not need indexical relativism, but much more prosaic views, to make sense of what seem to be pervasive phenomena involving indexicals. Second, I show that MacFarlane's arguments are not sound and offer alternative arguments based on indexical relativism's inability to account for most construals of faultless disagreement and retraction. My point is that MacFarlane's arguments are only effective against a particular version of the target theory, but not against indexical relativism in general. I use Cappelen's (2008a, 2008b) and Weatherson's (2009) views about certain kinds of imperatives and indicative conditionals respectively as examples of actual proposals that I think can be deemed varieties of indexical relativism but nevertheless survive MacFarlane's arguments against the corresponding approach to predicates of personal taste. In consequence, I suggest to develop indexical relativism 
about predicates of personal taste along the lines of Cappelen's and Weatherson's approaches. Even Cappelen's and Weatherson's proposals, though, find trouble when trying to accommodate faultless disagreement in most of its construals, and Weatherson's finds trouble with retraction too.

The structure of this paper is as follows. In section 2, I introduce both nonindexical and indexical relativism, briefly state my reasons for choosing this nomenclature, and contrast indexical relativism with a number of alternatives with which it might be confused in order to arrive at an accurate definition. In section 3, I present and discuss MacFarlane's arguments against indexical relativism. In section 4, finally, I argue that, even if MacFarlane's arguments are not sound, indexical relativism has the problems with faultless disagreement and retraction advanced above.

\section{Indexical Relativism}

Indexical relativism is best understood in contrast with the most widespread version of relativism, i.e., nonindexical relativism. In this section, I introduce both theories, which MacFarlane calls "content relativism" and "truth relativism" respectively, make some remarks about my preference for the "indexical"/"nonindexical" nomenclature, and offer a definition of indexical relativism that leaves out other views with which the theory might be confused.

MacFarlane takes the relativization of sentential truth to contexts of assessment to be the essential feature that any relativist view must be able to implement (MacFarlane 2014, pp. 64-65). For instance, the truth-value of the sentence

\section{(1) Licorice is tasty.}

as used at context $c$ and assessed from context $c^{\prime}$, has to depend on $c^{\prime}$ if our theory is to qualify as a variety of relativism. MacFarlane in particular obtains this result by postulating that (1) expresses at $c$ a proposition whose truth-value is relative to c' (MacFarlane 2014, pp. 90-92) and calls the theory that features this commitment "truth relativism". This is the theory that he defends. However, relativizing propositional truth-value to contexts of assessment is not the only possible move that has the relativization of sentential truth-value to contexts of assessment as its result. As MacFarlane himself acknowledges, we can get to the same place by relativizing what proposition is expressed by a given sentence to the context of assessment (MacFarlane 2014, p. 73; see also Percival 1994, pp. 192-193 for a similar point). If we do so, what proposition (1) expresses will depend on $c$ '. Since the truth-value of (1) will depend on the proposition it expresses, it will depend on $c^{\prime}$, as required from a relativist view. MacFarlane calls the theory that we obtain when we relativize the proposition expressed to contexts of assessment "content relativism" (for uses of this label in arguably the same sense, see Egan, Hawthorne \& Weatherson 2005, p. 154; Cappelen 2008a, p. 266; 2008b, pp. 23-24; Egan 2009, p. 274; 2011, p. 226; López de Sa 2011, p. 154). It is to this theory that this paper is devoted. 
As Weatherson (2009, pp. 341-342) does, I suggest to replace the labels "truth relativism" and "content relativism" with "nonindexical relativism" and "indexical relativism" respectively, ${ }^{1}$ drawing on MacFarlane's own use of the labels "nonindexical contextualism" and "indexical contextualism". Indexical contextualism is the theory according to which what proposition (1) expresses depends on $c$, and nonindexical contextualism is the theory according to which (1) expresses at $c$ a proposition whose truth-value is relative to $c$ (MacFarlane 2014, pp. 88-90). Note that the context of assessment plays in content relativism the exact same role that the context of use plays in indexical contextualism, as well as the exact same role in truth relativism that the context of use plays in nonindexical contextualism. I think this makes my terminological suggestion reasonable, and I also share Weatherson's interest in having a "compositional naming scheme" (Weatherson 2009, p. 341). The words "contextualism" and "relativism" make reference to what context is the relevant one, while the words "indexical" and "nonindexical" make reference to the role it plays.

As MacFarlane notes, it is not possible to talk of "the context of assessment" in the same sense in which we talk of "the context of use", for there is a potentially infinite number of contexts from which we might assess the proposition expressed by a single utterance (MacFarlane 2014, pp. 61-62) or, in this case, what proposition has been expressed. The consequence, as Field notes, is that in relativism we can find utterances that cannot be said to be accurate or not (Field 2009, p. 273). In indexical relativism, in particular, this happens when what proposition is expressed does not depend on the context of use, but on the context of assessment.

This is a first, tentative definition of indexical relativism that might be taken to encapsulate the idea that the context of assessment plays a role in the determination of the proposition expressed:

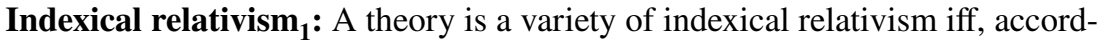
ing to it, the pair composed of the sentence and the context of use does not uniquely determine a proposition.

However, this definition is not adequate. If embracing indexical relativism amounted to thinking that sentences and contexts of use do not uniquely determine propositions, it would be equivalent to much more plausible theories that can be found in the market. We will thus need to revise our definition of indexical relativism accordingly.

The first theory from which indexical relativism should be distinguished is what MacFarlane calls "content pluralism", i.e., the view that a single utterance can express several propositions at the same time (MacFarlane 2014, p. 74). ${ }^{2}$ MacFarlane illustrates this view with the case of a marine drill sergeant who says to one hundred assembled recruits:

(3) If your mother knew the pain I am going to put you through, she would never have let you enlist.

\footnotetext{
1 Besides "indexical relativism" and "content relativism", the theory to which this paper is devoted has also been dubbed "expressive relativism" (MacFarlane 2005, p. 312).

2 Following Cappelen and Lepore (1997, 2003, 2004), Cappelen calls this view "speech act pluralism" (Cappelen 2008b, pp. 33-34).
} 
The sergeant's utterance expresses a hundred different propositions, but it does not depend on each recruit's context what these propositions are-they can all agree about both their number and content. This makes content pluralism relevantly different from indexical relativism. Of course, the sergeant example can also be construed so as to make the sergeant perform a plurality of utterances at the same time, each of them expressing a unique proposition. This would result in the second alternative to indexical relativism, which Cappelen calls "utterance pluralism" (Cappelen 2008b, pp. 34-35). As Egan (2009, p. 270) notes, the decision between content pluralism and utterance pluralism is to some extent terminological, as it follows from both theories that, when the sergeant talks, a plurality of propositions is communicated. The contrast between indexical relativism and any of these two theories suggests revising the definition of the former so that a single utterance does not uniquely determine a set of propositions, where the limiting case is that in which the set consists of a single proposition:

Indexical relativism : $_{2}$ A theory is a variety of indexical relativism iff, according to it, the pair composed of the sentence and the context of use does not uniquely determine a set of propositions.

If we follow MacFarlane, the third kind of proposals from which indexical relativism should be distinguished are those that bifurcate context (MacFarlane 2014, p. 62 , n. 24). ${ }^{3}$ This move has been suggested as a way of making sense of the contents of two different kinds of utterances. Consider, first, an utterance of

(4) I am not here now.

recorded by an answering machine. In cases like this, speakers intend their utterances to be assigned a content relative to both the context of use, which as usual determines the reference of "I" and "here", and a context of interpretation, which determines the reference of "now" (Predelli 1996, 1998a, 1998b). Second, we can also introduce the context of thought as the one relative to which content should be assigned to sentences in the historical present, such as

(5) Fifty-eight years ago to this day, on 22 January 1944, just as the Americans are about to invade Europe, the Germans attack Vercors. (Schlenker 2004)

Both in the answering machine case and in that in the historical present, MacFarlane claims, there is a context that is fixed by the speaker's intentions. This seems indeed to be the case when we use sentences in the historical present. What makes indexical relativism what it is, according to the definition we are working with now, is that it refuses to assign sets of propositions to utterances once and forever. Utterances of sentences in the historical present such as (5) are assigned a proposition once and forever, viz. the one containing the historical time. Thus, indexical

\footnotetext{
3 In fact, MacFarlane's discussion of these proposals contrasts them with nonindexical relativism. However, the same features he highlights distinguish these views from indexical relativism.
} 
relativism can be effectively distinguished from proposals that involve a context of thought.

But this is not so straightforward when it comes to answering machine cases. When recording a message, the speaker may have in mind a context of interpretation, but this is not what fixes the content of the utterance. If the utterance we are taking into account is the original one, then it does not determine a unique set of propositions, and we are thus facing a variety of indexical relativism as we are understanding it now. The idea that speakers can have a notion as to what contexts count as legitimate is not incompatible with indexical relativism. To see this, consider how Cappelen's brand of indexical relativism, which will be discussed in the next section, includes the notion of a range of admissible contexts of assessment (Cappelen 2008b, p. 26). However, the fact that indexical relativism is compatible with the speaker's having any particular context or range of contexts in mind does not mean that answering machine cases have to be accounted for in an indexical relativist way, as they are also susceptible of being treated as cases in which an utterance bomb has been planted (Egan 2009, pp. 257-259). Each time the answering machine plays the recorded message, we could say, a new utterance takes place; and each of these utterances expresses a unique proposition. These utterances share the speaker — the person who recorded the message — ${ }^{4}$ and the location — wherever the answering machine is-, but not the time of utterance. Although "I" refers every time to the person who recorded the message and "here" always refers to the place where the answering machine is located, thus, the reference of "now" changes from replaying to replaying. Understanding answering machine cases as cases in which an utterance bomb has been planted does not require indexical relativism, as doing so does not involve any kind of relativization to contexts of assessment. In fact, we do not even need utterance pluralism to implement an account in terms of utterance bombs. Any traditional theory according to which pairs of sentences and contexts of use uniquely determine propositions will do. ${ }^{5}$

Once we have shown our definition to exclude proposals involving utterance bombs, it is tempting to see the difference between indexical relativism and content/ utterance pluralism as one as to the cardinality of the set of possible contexts of assessment. In content/utterance pluralism, there is a definite number of such contexts - there will be as many of them as recruits are listening to the sergeant say (3) "If your mother knew the pain I am going to put you through, she would never have let you enlist", for instance. In indexical relativism, by contrast, the number of possible contexts of assessment is indefinite:

\footnotetext{
${ }^{4}$ Egan (2009, p. 257) takes the answering machine to be the speaker in cases like these, but this seems wildly implausible: if it were, utterances of "I am here now" would always be false, for the answering machine $i s$ there every time the message is played. Sidelle's (1991) view about deferred utterances, which is akin to Egan's in all respects except this, seems preferable to me in this regard.

5 A possible worry is that this overgeneralizes, so that every case that might be treated in indexical relativist terms can be understood as one in which an utterance bomb has been planted. But, while it is plausible to think that a new utterance takes place each time the answering machine replays the message, it is far less natural to think that the same thing happens, for instance, each time someone wonders whether (1) "Licorice is tasty" is true or false.
} 
Indexical relativism : $_{3}$ A theory is a variety of indexical relativism iff, according to it, the pair composed of the sentence and the context of use does not uniquely determine a definite set of propositions.

But we can have indefinite contexts without indexical relativism. This is what happens in the fourth alternative to indexical relativism, which stresses the role of what Egan calls "audience sensitivity" (Egan 2009, p. 256). ${ }^{6}$ According to Egan, the contribution made by some uses of context-sensitive vocabulary to the content of the sentences in which they occur is sensitive not merely to features of the speaker's situation, but also to features of the situations of particular audience members. For instance, the sentence

\section{(6) Jesus loves you.}

written on a billboard, expresses a different proposition for each person who reads it (Egan 2009, pp. 259-261).

One might argue that (6) is too similar to (3) "If your mother knew the pain I am going to put you through, she would never have let you enlist" to be an example of a different phenomenon, so that what Egan proposes is actually a variety of content pluralism. To see the difference between the two cases, note that the audience is definite in MacFarlane's example, while it is indefinite in Egan's. We can know in advance who the receptors of the sergeant's utterance will be, but it is not possible to anticipate who will read the billboard. Thus, the content of (6) is not determinate in the way in which the one expressed by the sergeant is. However, this does not make Egan's view a variety of indexical relativism, as López de Sa (2011, pp. 113-114) argues, for recipient and assessor do not always coincide. This is a good thing, for it means that we do not need indexical relativism, which this paper ultimately argues is implausible, to make sense of mundane cases like (6). If we take a third-person stance and assess an exchange between an utterer and a recipient of (6), we will take it to convey the proposition that Jesus loves that person, not that Jesus loves $u s$, and other assessors will be likely to agree with us. If we are indexical relativists about "tasty", by contrast, we will take (1) "Licorice is tasty" to express a proposition containing a personal taste standard determined by our context, not the recipient's. Even if, unlike in the sergeant's example, we cannot make a list of the propositions that the billboard expresses, assessors do not seem to get into the picture in any of the two cases.

The fact that we can revise our conception of a context of use to include the hearer's features among those that individuate it, as Egan (2009, pp. 273-274) proposes to do, suggests that relativizing to hearers is not the same as relativizing to assessors, and this allows us to offer a final definition of indexical relativism:

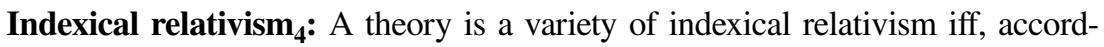
ing to it, the pair composed of the sentence and the context of use, understood as including the hearer's features, does not uniquely determine a set of propositions.

\footnotetext{
${ }^{6}$ Cappelen (2008b, p. 30) calls Egan's position "content relativism", but what follows is intended to show, drawing on López de Sa's (2011, pp. 113-114) argument, that such a view does not belong to the extension of this label.
} 
This definition affords us the desired result, as it makes indexical relativism different from content/utterance pluralism and views that bifurcate context, postulate utterance bombs, or rely on audience sensitivity.

Other views with which indexical relativism could be confused are those that take what the content of an utterance is to be a vague issue (see, for instance, Cappelen 2008a, pp. 267-268; von Fintel and Gillies 2008), those that introduce clouds of propositions as the contents of certain utterances (see Braun and Sider 2007; Buchanan 2010; von Fintel and Gillies 2011), and Perry's (2001) multipropositionalism (see Clapp and Lavalle Terrón 2019, pp. 934-937 for a brief summary of the position). As it stands, our definition is already enough to distinguish indexical relativism from these proposals. To see the difference between indexical relativism and the first kind of view, consider the fact that, when confronted, we do not stand by our loose descriptions of what someone has said but retreat to tighter ones, something that should not be expected if indexical relativism underlied our reporting practices (MacFarlane 2014, pp. 74-75). In the second place, although no single proposition can be assigned to an utterance in any of the views involving clouds of propositions, in all of them there is a set of propositions that can be assigned, and it is a settled matter what it is. These theories are in this sense similar to content pluralism, although there will likely be differences between the two kinds of view as to the norms governing assertion and uptake. Finally, a single utterance expresses a number of propositions according to multipropositionalism, just like indexical relativism claims. However, two assessors can agree about what these propositions are, as it was possible for them to do in MacFarlane's sergeant example. Thus, indexical relativism is not like multipropositionalism either.

Note that proposals involving clouds of propositions will be different from indexical relativism even if the hearer plays a part in determining the content of the utterance, as she does in King's (2014) proposal. According to King, the range of values that the contextually sensitive expression at issue takes will include those that a "competent, attentive, reasonable hearer who knows the common ground of the conversation at the time of utterance" (King 2014, p. 102) would know the speaker to intend. But we do not need to take any particular person other than the speaker into account to establish what an ideal hearer would understand. Thus, just like in Braun and Sider's, Buchanan's, and von Fintel and Gillies' views, each utterance will fix a unique set of propositions.

\section{The Problem with Reports}

In this section, I present MacFarlane's two arguments against indexical relativism. At the end of the day, however, MacFarlane's arguments do not strike me as conclusive, as I will explain. I will devote most of the section to the first argument, which is that, once we treat "tasty" in an indexical relativist way, we are forced to do the same with personal pronouns (and, as we will see, proper names), and these clearly fall outside of the theory's scope. My response to this argument will be that indexical relativism about personal pronouns (and proper names) only follows from the corresponding theory about "tasty" if we understand synonymity as identity of content. If the indexical relativist understands it as identity of character instead, as 
I think she should do, she will be able to apply the theory to "tasty" without being forced to apply it to the problematic cases as well. My (briefer) response to MacFarlane's second argument, which is that the indexical relativist denies speakers authority as to the content of their assertions, will be parasitic on my response to the first. Once she understands synonymity as identity of character, the indexical relativist will be able to attribute authority to speakers in exactly the same cases as MacFarlane.

MacFarlane's (2014, p. 73) first argument to the effect that indexical relativism is implausible when it comes to explaining how sentences containing "tasty" work is the following. Remember (1):

\section{(1) Licorice is tasty.}

Let us suppose that Yum utters (1), which is true according to her standard of personal taste and false according to Yuk's. MacFarlane considers two possible explanations for this. One is that the proposition expressed by Yum is true relative to her standard and false according to Yuk's. This is what the nonindexical relativist would say. The other explanation is that, from her perspective, Yum has expressed the proposition that licorice is pleasing to her tastes, while, from Yuk's perspective, Yum has expressed the proposition that licorice is pleasing to Yuk's tastes. But let us suppose that Yum now says

(2) I asserted that licorice is pleasing to my tastes.

If we are indexical relativists about "tasty", MacFarlane says, this will again be true according to Yum's standard, false according to Yuk's. After all, only from Yum's perspective was the proposition expressed that licorice is pleasing to Yum's tastes. But now, the indexical relativist explanation seems highly implausible. For, if it were true, it would imply that, from Yuk's perspective, Yum would have expressed the proposition that she had asserted that licorice is pleasing to Yuk's tastes, which is simply not how "my" works, regardless of how "tasty" could work-by uttering (2), Yum is talking about Yum's tastes, not about Yuk's. Thus, MacFarlane says, “(i) $t$ is difficult to make sense of (indexical) relativism without countenancing (nonindexical) relativism as well" (MacFarlane 2014, p. 73). That is, one could of course explain (1) in an indexical relativist way and (2) in a nonindexical relativist way, but why then not become a nonindexical relativist from the beginning? ${ }^{7}$ A possible

\footnotetext{
7 MacFarlane's argument may remind us of an objection to indexical relativism about epistemic modals posed by Egan, Hawthorne and Weatherson (2005). They claim that indexical relativism renders implausible readings of sentences containing epistemic modals embedded under the scope of a belief operator, such as "Moriarty believes that Holmes might be in Paris". In particular, this sentence is predicted to express the proposition that Moriarty believes that, as far as the assessor knows, Holmes is in Paris; however, this conflicts with our pretheoretical intuitions (Egan, Hawthorne and Weatherson 2005, p. 155; for a reply, see Weatherson 2009, p. 350). In a sense, MacFarlane's argument against indexical relativism about "tasty" points toward the same direction as Egan, Hawthorne and Weatherson's-indexical relativism about reports, whether attitude or speech reports, delivers weird results.
} 
answer is that, while (1) includes the word "tasty", (2) does not, and it is the occurrence of this word that makes a sentence suitable for an indexical relativist treatment. But (2) can be easily paraphrased as

(7) I asserted that licorice is tasty to me.

If we do so, MacFarlane should take indexical relativism to predict that (7), as used by Yum and assessed by Yuk, expresses the proposition that Yum asserted that licorice is tasty to Yuk, which is simply not how "me" works. And now, if the indexical relativist wants her proposal to apply to (1) and not to (7), she has to postulate a distinction between uses of "tasty" that seems unwarranted. Because now there does seem to be no relevant difference between (1) and (7), not beyond the fact that, in the latter, "tasty" appears embedded under "I asserted that"; and semantic innocence (see Davidson 1968; Pietroski 1996) requires us not to assign different meanings in cases like this. In what follows, I proceed as if MacFarlane's argument made use of (7) rather than (2). My argument, of course, can be reproduced for (2) too.

MacFarlane's seems a knock-down argument, but I think it relies on a contentious assumption. It takes the indexical relativist to make (1) "Licorice is tasty" synonymous with

(8) Licorice is pleasing to my tastes.

or, if we choose to base the argument on (7) "I asserted that licorice is tasty to me" instead of (2) "I asserted that licorice is pleasing to my tastes", with

(9) Licorice is tasty to me.

Given this, MacFarlane's argument can be reconstructed as follows. Consider

(10) I asserted that licorice is tasty.

If (1) and (9) are synonymous, as MacFarlane takes the indexical relativist to assume, (7) will be true whenever (10) is true, and false whenever (10) is false. Thus, (7) will be true as assessed from Yum's context, because (10) is-relative to that context of assessment, (10) expresses the proposition that Yum asserted that licorice is tasty to Yum, and this is true. But (7) will also be false as assessed from Yuk's context, since, relative to that context, (10) expresses the proposition that Yum asserted that licorice is tasty to Yuk, which is false. So (7) is assessment-sensitive. If we use indexical relativism to explain this, we will have to postulate a strange behavior for "me". If we turn to nonindexical relativism instead, why not do so for (1) as well?

However, (1) "Licorice is tasty" and (9) "Licorice is tasty to me" are synonymous only if we keep Yum's context fixed as the context of assessment. 
Relative to this context, (1) and (9) express the same proposition-the proposition that licorice is tasty relative to Yum's personal taste standard. This will happen, in general, whenever the context of assessment coincides with the context of use. But (1) and (9) will not express the same proposition if this is not the case. Take, for instance, the case in which Yum utters (1) and Yuk assesses this utterance. Here, the context of use is Yum's, while the context of assessment is Yuk's. In this case, the proposition expressed will be that licorice is tasty relative to Yuk's standard. But if Yum's utterance is one of (9), again as assessed by Yuk, the proposition expressed will now be that licorice is tasty relative to Yum's standard. Synonymity with respect to a particular context of assessment is not strict synonymity, and we need the latter to hold between (1) and (9) if we want Yum to speak truly when she utters (7) "I asserted that licorice is tasty to me" in reference to her previous assertion of (1).

To see this, note that we require two sentences to express the same proposition at each context of use to declare them synonymous. Suppose Yum utters

(11) I ate too much licorice.

and consider an utterance, also of Yum's, of

(12) Yum ate too much licorice.

(11) and (12) are not synonymous because, although they express the same proposition at a context in which Yum is the speaker, they would not do so if this were not the case. In other words, we need identity of character, rather than identity of content, to talk about synonymity (see Kaplan 1977/1989, p. 533).

In fact, I think that the requisite is for (11) and (12) to be synonymous is for them to express the same proposition with respect to each possible pair of context of use and context of assessment; however, since none of them is sensitive to the latter, the reason they are not synonymous is simply that they express different propositions at least at some contexts of use. The requisite for (1) "Licorice is tasty" and (9) "Licorice is tasty to me" to be synonymous would be the same. (1), however, is sensitive to the context of assessment, so it would be synonymous with (9) only if the latter were sensitive to the context of assessment in the same way. But this is not the case. Thus, (1) and (9) are not synonymous.

Moreover, note the following. Suppose that, as assessed from Yuk's context, Yum's utterance of "me" in (7) "I asserted that licorice is tasty to me" indeed refers to Yuk, and consider the reference of "I" in the same sentence. It could either refer to Yum or refer to Yuk. If "I" referred to Yum, the referent of "I" would be different from that of "me", which is weird. If "I" referred to Yuk instead, it would have the same referent as "me", but things would be even weirder. Regardless of how tolerant one wanted to be as to the standard involved in (7), it would be absurd to claim that Yum can use 
this sentence to say that Yuk asserted something. ${ }^{8}$ Of course, "I" refers to Yum, but this yields no weird results, for, as shown above, "me" refers to Yum too.

If (1) "Licorice is tasty" is not synonymous with (9) "Licorice is tasty to me", as I claim, Yum will not have spoken truly when she utters (7) "I asserted that licorice is tasty to me", regardless of the context of assessment, if the utterance she is referring to is one of (1). For, in uttering (1), it was only relative to Yum's context of assessment that she was asserting that licorice is tasty to her. Relative to other contexts of assessment, she was asserting other propositions. For (7) to be true at a particular context of assessment, (1) and (9) have to be synonymous at all contexts of assessment, not only at that one. This is what it would mean for (9) to be a good translation of (1). For (7) to be true, therefore, Yum's utterance of (1) would have to have expressed, relative to each context of assessment that we might consider, the proposition that licorice is tasty to Yum. Since there are contexts of assessment, such as Yuk's, relative to which this is not the case, (7) is false. We thus do not have the problem of explaining how (7) can be true relative to some contexts of assessment and false relative to others, because it is false all across the board. MacFarlane's dilemma does not have the chance to arise.

For the same reason, all of the following sentences, as uttered by Yum, are false from every context of assessment:

(13) I asserted that licorice is pleasing to your tastes.

(14) I asserted that licorice is tasty relative to Yum's standard.

(15) I asserted that licorice is tasty relative to Yuk's standard.

To see this, note that none of

(16) Licorice is pleasing to your tastes.

(17) Licorice is tasty relative to Yum's standard.

(18) Licorice is tasty relative to Yuk's standard. ${ }^{9}$

is synonymous with (1) "Licorice is tasty". (1) is assessment-sensitive, while (16-18) are not. This blocks the possibility that MacFarlane's argument is replicated, for instance, by taking (14) to be the content of Yum's assertion of (10) "I asserted that licorice is tasty". One cannot say that (14), as uttered by Yum, is true from her context of assessment but false from Yuk's, so either "Yum" means Yuk as assessed from Yuk's context or we better explain the divergence in truth-value in a nonindexical relativist way. One cannot say this because there is no divergence in truth-value-(14), as uttered by Yum, is false both from Yum's context and from Yuk's.

The idea that indexical relativism does not take assessment-sensitive sentences to be synonymous with sentences featuring personal pronouns (or proper names)

\footnotetext{
8 Thanks to an anonymous reviewer for Philosophia for suggesting this objection to me.

9 Thanks to the reviewer for Philosophia mentioned in the previous footnote for making me consider these candidate translations of (1) "Licorice is tasty" as well.
} 
may be clearer for cases in which paraphrases without personal pronouns (or proper names) are much more natural. Cappelen (2008b), in particular, proposes to embrace a form of indexical relativism for predicates used in certain kinds of imperatives. Consider, for instance, the instruction

(19) If a dangerous object is found in carry-on luggage, immediately contact a security officer. (Cappelen 2008b, p. 30)

Cappelen claims that the utterer of (19) should intend the extension of "dangerous" to vary from one interpreter to another, where the range of admissible interpreters is restricted to those in a condition to carry out the instruction. Or consider laws, which, according to a mainstream view in legal theory, are intended by those who write them to have varying interpretation over time. Here, the range of admissible interpreters is restricted to those who stand sufficiently high in the judicial hierarchy. Both in the case of instructions and in the case of laws, speakers cannot anticipate the content of their utterances with respect to an arbitrary admitted context of interpretation $^{10}$ (Cappelen 2008b, pp. 30-31). Cappelen's context of interpretation can be assimilated to MacFarlane's context of assessment, inasmuch as a single utterance, understood as determining the hearer as well, does not determine a fixed set of propositions in Cappelen's view. Thus, Cappelen's proposal can be read as a variety of indexical relativism.

MacFarlane could try to replicate his argument for (19), as follows. Alice and Beth work together at an airport's security control. After seeing something suspicious on the screen, they open a passenger's carry-on luggage and find a disposable razor among her belongings. For Beth, a disposable razor is the kind of thing that should be confiscated if found in carry-on luggage, but not the kind of thing that warrants contacting a security officer. Alice, for her part, thinks that you never know with what intention a passenger tries to sneak a disposable razor in a flight and it is never unwise to contact a security officer. After a brief discussion, Alice gives in and accepts to just confiscate the razor, even if she still thinks that (19) requires her to call security. Thus, (19) has been obeyed from Beth's perspective and disobeyed from Alice's. Now, suppose that Alice says

(20) The rule says that, if a disposable razor is found in carry-on luggage, we should immediately contact a security officer.

This is true from Alice's perspective, but not from Beth's- she thinks disposable razors do not fall under the extension of "dangerous object". This might be so because, from Alice's perspective, the extension of "dangerous object" in (19) includes disposable razors, while, from Beth's perspective, it does not. What is important here is that, just like happened in the revised example involving "tasty", (20) does not include any expression whose reference we intuitively take to be fixed by the context of use, like "my". Thus, MacFarlane's argument cannot be replicated here.

$\overline{10}$ Not to be confused with Predelli's context of interpretation (see section 2). 
A parallel argument can be reconstructed for indicative conditionals, which are the kind of sentences for which Weatherson's (2009) account is intended. According to Weatherson, the content of

\section{(21) If $p$, then $q$.}

is $\mathrm{C}(p, q, X)$, where $X$ are the "background" propositions relative to which the conditional is assessed (Weatherson 2009, p. 341). That is, (21) expresses different propositions depending on the context of assessment, with each of them containing the body of propositions relative to which the conditional is assessed. Weatherson uses the label "indexical relativism" like I do and characterizes the theory to which it applies in terms similar to mine. However, at some points he writes as if the parameters determined by the context of assessment were necessarily those of the assessor. But the values that a context provides are not necessarily those that figure in the index of the context; the personal taste standard determined by the context of assessment, in particular, might not be that of the assessor, but the one that is relevant in that context, whether or not the assessor endorses it (see Pérez-Navarro 2021). Still, Weatherson's proposal is such that we need the context of assessment to determine what proposition has been expressed; thus, I think it deserves to be called a version of indexical relativism.

Given Weatherson's account of the content of (21),

\section{I asserted that $\mathrm{C}(p, q, X)$.}

would also express different propositions depending on the context of assessment, and the body of propositions would again be determined by the context of assessment. But there is no "my" in (22), so it allows for an indexical relativist treatment.

Let us now briefly turn to MacFarlane's second argument against indexical relativism, which is that it "seems to get the phenomena wrong":

If Yuk were to claim that Yum had asserted that licorice is pleasing to Yuk's tastes, Yum would simply deny this, and ordinarily this denial would be taken to be authoritative. (When there is doubt about what speakers have asserted, we can ask them to clarify, and barring worries about sincerity, we take them at their word.) In support of his claim, Yum could point out that her basis for making the assertion was that licorice tasted good to her, and that she was aware of the deep differences between her tastes and Yuk's. So it would have been completely irrational for her to assert that licorice is pleasing to Yuk's tastes. (MacFarlane 2014, p. 74)

This argument is reminiscent of Egan, Hawthorne and Weatherson's (2005, p. 156) objection to indexical relativism that it is not clear what role it would reserve for assertion. In Stalnaker's theory, the role of an assertion is to add the asserted proposition to the common ground (Stalnaker 1978). But what proposition should be added if there is no such thing as the asserted proposition? This objection has been met by both Cappelen (2008b, p. 35-40) and Weatherson (2009, pp. 343-344). 
Whether or not their replies are convincing, I will leave this kind of objection aside here. But I want to respond to MacFarlane's second argument along lines similar to the ones along which I have responded to the first. Presumably, MacFarlane considers the situation in which Yum utters (1) "Licorice is tasty" and Yuk says

You asserted that licorice is pleasing to my tastes.

or, if we choose to translate (1) as (9) "Licorice is tasty to me",

(24) You asserted that licorice is tasty to me.

For this to be true, (1), as uttered by Yum as assessed by Yuk, would have to be the synonymous with (9), as uttered and assessed by Yuk. But we have already seen that the indexical relativist does not have to take (1) to be synonymous with (9), as (9) is not assessment-sensitive. Thus, it is just not true that, from Yuk's perspective, Yum has asserted that licorice is tasty to Yuk. If this is so, Yuk will take Yum's denial as authoritative, which is the desirable result. As we have seen, however, it does not follow from this that Yuk should take Yum's utterance of (7) "I asserted that licorice is tasty to me" as authoritative too, as Yum has only said that licorice is tasty-neither that it is tasty to Yuk, nor that it is to Yum.

MacFarlane's arguments against indexical relativism therefore fail. If we understand synonymity as identity of character, it will no longer follow from indexical relativism about (1) "Licorice is tasty" either that (7) "I asserted that licorice is tasty to me" is assessment-sensitive or that (24) "You asserted that licorice is tasty to me" is true as uttered and assessed by Yuk. Does this mean that indexical relativism is a plausible option when it comes to accounting for the behavior of predicates of personal taste, imperatives, or indicative conditionals? I do not think so. Even if we can reply to MacFarlane's arguments, indexical relativism seems for the most part unable to cope with the phenomena that have standardly been used to test theories in this area-faultless disagreement and retraction. In the next section, I discuss how indexical relativism deals with them.

\section{Faultless Disagreement and Retraction}

The disadvantages of indexical relativism are not as worrying as they might seem if we just take MacFarlane's arguments into consideration. This is why, in this section, I want to produce some further evidence against the theory. In particular, I confront indexical relativism with the arguments that have traditionally been used to motivate its nonindexical sibling, which have to do with the latter's capacity to account for two phenomena-faultless disagreement and retraction. I will first check if indexical relativism can account for these phenomena in nonindexical relativism's terms, i.e., as requiring incompatibility of contents. Later, however, I will discuss whether indexical relativism can account for faultless 
disagreement understood in a few alternative ways and for retraction as it should be conceived according to each of these views.

Let us start with faultless disagreement. Consider the following dialogue. Alice and Beth are trying to choose a candy that they can share. Alice utters (1) "Licorice is tasty" and Beth replies:

No, it isn't.

Alice and Beth can both have a right to say what they say, and there is no clear sense in which at least one of them has to have made a mistake. Moreover, it is hard to imagine a fact that could settle their dispute, something that would be easier to do if, for instance, they discussed licorice's composition. Disagreements such as this one are called "faultless disagreements" (Kölbel 2004). To see what indexical relativism would make of this case, suppose that Alice utters (1) at context $c_{A}$ and that Beth hears it from context $c_{B}$. As assessed from $c_{A}$, (1) expresses the proposition that licorice is tasty according to the personal taste standard determined by that context, while, as assessed from $c_{B}$, it expresses the proposition that licorice is tasty according to the personal taste standard determined by that context. This would allow (1) to be true according to Alice, since the personal taste standard determined by her context sanctions her judgment. But it would also allow (1) to be false according to Beth, since licorice is not tasty according to the personal taste standard determined by her context, thus making it appropriate for her to reply with (25).

The problem with indexical relativism's account of this case is that it fails to characterize the conversation between Alice and Beth as a disagreement, at least if it wants to do so in the same terms as nonindexical relativism-as requiring incompatibility of contents. Here, $c_{A}$ and $c_{B}$ are both contexts of assessment. $c_{A}$, in particular, is both the context of use and one of the contexts of assessment. Hence, according to the indexical relativist, (1) expresses one proposition relative to one context of assessment and a different one relative to another. These propositions are not incompatible-licorice may be tasty according to one standard and not tasty according to another. If incompatibility of contents is needed to have a disagreement, as nonindexical relativism assumes, then indexical relativism predicts that the apparent disagreement between Alice and Beth, although faultless, is not a true disagreement. We will later see how indexical relativism would stand with respect to disagreement if the latter did not require incompatibility of contents.

Indexical relativism's problem with disagreement understood as incompatibility of contents becomes especially acute when it comes to disagreements about reports. Unlike theories that rely on audience sensitivity (see section 2), indexical relativism makes faultless exchanges about the content of an assertion possible. But in doing so it renounces rendering such exchanges as instances of disagreement, as it does with exchanges such as the one that takes place when Alice utters (1) and Beth utters (25) (see Chrisman 2007, pp. 228-230). Suppose Alice utters

(10) I asserted that licorice is tasty. 
and Beth replies:

$$
\text { No, you didn't. }
$$

However we choose to analyze (10), indexical relativism will make its content include a personal taste standard determined by $c_{A}$, while the content of (26) will include one determined by $c_{B}$. If these two standards are different, Alice and Beth will not even be talking about the same thing. This problem is raised by the same kind of cases considered by MacFarlane, but it does not depend on constructing indexical relativism as committed to the idea, discussed in section 3, that, in saying that licorice is tasty, one is saying that it is tasty to oneself.

A possible objection to the argument above is this. I have been assuming throughout that, no matter the relativity of the truth-value of sentences like (1) "Licorice is tasty" and (10) "I asserted that licorice is tasty", whether Alice and Beth disagree or not is itself a settled matter. However, we could follow Cappelen (2008a) in saying that agreement and disagreement judgments are themselves relative and express different contents with respect to different interpreters. If this were so, we could not say that indexical relativism fails to account for faultless disagreement because it discards disagreement between Alice and Beth tout court. From Alice's perspective, she is disagreeing with Beth, because Alice has expressed the proposition that licorice is tasty according to Alice's standard and Beth has expressed the proposition that licorice is not tasty according to that very same standard. For similar reasons, Alice and Beth are disagreeing from Beth's perspective too.

I concur that agreement and disagreement judgments are best viewed as interpreter relative. However, if as we have been doing throughout this paper we keep understanding "interpreter" as "assessor", Alice and Beth should not only disagree from either's perspective, but also from ours. Of course, this does not mean that we have to include our own taste standard as part of the content that we attribute to Alice's and Beth's assertions. The relevant standard when dealing with Alice's assertion can be one, and the relevant standard when dealing with Beth's assertion can be another, and none of these has to be our own. But this means that, from our perspective, the contents of Alice's and Beth's assertions are not incompatible, so, given the relativist assumption that disagreement requires incompatibility of contents, they do not disagree. Thus, although there is a salient sense (disagreement from the speaker's perspective) in which Alice and Beth disagree, there is another (disagreement from an external perspective) in which they do not. It can be easily proven that nonindexical relativism, by contrast, makes Alice and Beth disagree in both senses.

This was to be expected. What makes nonindexical relativism able to deal with the faultlessness of faultless disagreement, after all, is the fact that it relativizes sentential truth to contexts of assessment, not the nonindexical way in which it does so. However, the nonindexical component of nonindexical relativism is what allows it to account for the fact that faultless disagreement is a kind of disagreement. By lacking such component, indexical relativism makes the propositions under discussion compatible. So, just like indexical contextualism, indexical relativism seems unable 
to characterize faultless disagreement as a kind of disagreement if doing so requires incompatibility of contents.

Relativization of sentential truth to contexts of assessment not only allows nonindexical relativism to account for the faultlessness of faultless disagreement, but also to deal with retraction, i.e., the speech act that one performs in saying "I take that back" or "I retract that" (MacFarlane 2014, p. 108), as it would make sense for Alice to do if at some point she uttered (1) "Licorice is tasty" but later changed her mind. So, in principle, indexical relativism seems fit to deal with retraction as well. If, at the later time, Alice assesses her utterance of (1), she will take such utterance to express the proposition that licorice is tasty according to her current personal taste standard. This will allow (1) to be false now, since, if the standard taken into account by Alice has changed, it will preclude finding licorice tasty. However, that indexical relativism is able to deal with retraction is merely illusory. For retracting a previous assertion involves changing one's mind, and indexical relativism is compatible with our judging false a proposition that we have always taken to be so. (1) is false now, but not because Alice has changed her mind about the truth-value of the proposition it originally expressed, but because it expresses a false proposition now. Hence, Alice is not strictly retracting: for an indexical relativist, her saying "I take that back" is compatible with her always having judged the same things as true or false. Indexical relativism about "tasty" thus seems unable to account either for faultless disagreement or for retraction in the way in which nonindexical relativism does.

We should be cautious, though, before extending this conclusion to forms of indexical relativism such as Cappelen's and Weatherson's, for theirs are not views about predicates of personal taste, but about some kinds of imperatives, in Cappelen's case, and about indicative conditionals, in Weatherson's. The conclusion that indexical relativism does not work, not even for the areas of language for which it has been most thoroughly defended, can only be reached if faultless disagreement and retraction are possible for certain imperatives and indicative conditionals too. As we will see next, it is relatively easy to build cases in which indicative conditionals give rise to faultless disagreements, as well as cases in which they can be retracted, but things are a little more complicated with imperatives.

Let us start with conditionals. Suppose Alice says:

(27) If Bernie Sanders becomes the next US president, things will be very different from the way they are now.

and Beth replies:

No, they won't.

Alice utters (27) because she puts a lot of weight on issues having to do with the distribution of wealth, so a future in which taxes on wealth are significantly higher qualifies as very different from the present for her. Beth, for her part, replies with (28) because she thinks a Sanders presidency will leave racist structures untouched, 
and this is the crucial test for change for her. I think it is fair to say that this is a case of faultless disagreement about indicative conditionals. Alice and Beth privilege different things when assessing the truth of (27), and there is no clear sense in which any of them can be said to be wrong. Indexical relativism predicts exactly this, as it takes (27) to be true with respect to $c_{A}$ and false with respect to $c_{B}$. However, it does so by claiming that, from Alice's point of view, the proposition expressed by (27) includes a set of propositions having to do with wealth distribution, while, from Beth's, it includes a set of propositions having to do with race equality. Thus, there is no single proposition about which Alice and Beth can be said to be disagreeing, so indexical relativism results unable to account for faultless disagreement.

It seems that indicative conditionals can be retracted as well. Imagine that, some time after Alice's utterance of (27), Sanders wins the election and becomes president of the US. Wealth is indeed distributed in a more just way thanks to higher taxes on those who earn more, but things stay pretty much the same race-wise. Alice finds that her life has not changed as much as she expected, so, when reminded of her utterance of (27), she says "I take that back". But what should the indexical relativist say she is taking back? According to indexical relativism, from her current point of view, what she originally expressed was a proposition that included race-related propositions, and she takes this proposition to be false now. But Alice has not changed her mind about the truth-value of any proposition. Thus, she is not retracting anything.

As I advanced above, it is a little trickier to build cases of faultless disagreement and retraction involving imperatives. The latter, in fact, are impossible to build. This is so because imperatives are not truth-evaluable, and truth plays a central role in standard characterizations of both faultless disagreement and retraction. But truth also plays a central role in the characterization of indexical relativism; thus, if indexical relativism about imperatives is not inconsistent by definition, the possibility of characterizing faultless disagreement and retraction without any reference to truth should not be straightforwardly ruled out. Just like we assess (typical) declaratives by establishing whether they are true or false in the actual world, I propose to understand assessment of imperatives to proceed by establishing whether a given course of action is in agreement with them or not. Thus, a disagreement about an imperative would be one as to whether someone who has followed a given course of action has complied with what the imperative requires or not. And some of these disagreements can be faultless.

For instance, I think that Alice and Beth's disagreement about whether contacting a security officer after finding a disposable razor is in accordance with (19) "If a dangerous object is found in carry-on luggage, immediately contact a security officer" is a faultless disagreement, as it is difficult to say that there is a fact of the matter as to which of them is right or wrong. Indexical relativism has no problem predicting this: (19) requires calling security from Alice's point of view, while it does not from Beth's. But indexical relativism is forced to say that there is no disagreement between Alice and Beth, for there is no single instruction (understood as the meaning of an imperative sentence) about whose consequences they disagree. So, again, indexical relativism about the kinds of imperatives with which Cappelen 
deals affords us faultlessness without disagreement understood as incompatibility of contents.

Two people can disagree without having ever met, and thus without the occurrence of any explicit marker of disagreement (see Cappelen and Hawthorne 2009, pp. 60-61). To say that two people disagree about whether a given course of action is in accordance with a certain imperative, it is enough that they behave in different ways, as Alice and Beth do. Retraction, by contrast, is directed toward a speech act, in such a way that the interpretation of "that" as referring to our taking a particular course of action to be in accordance with the instruction is just not available. For instance, if Alice's criterion evolves to match Beth's, and she no longer takes (19) to require calling security over a disposable razor, she will not say "I take that back" unless she had explicitly stated what she understood the instruction to require, and in this case it will be this utterance that she is retracting. Thus, it seems that the intended retraction of (19) is not possible. The conclusion is that indexical relativism about imperatives does not have a problem with retraction, for there is no phenomenon of retraction to start with for which it should account. Still, it has a problem with faultless disagreement, as shown above. So no form of indexical relativism actually proposed is completely devoid of disadvantages, which makes nonindexical relativism the strongest contender when trying to explain faultless disagreement and retraction in terms of incompatibility of contents.

Of course, not everyone accepts that faultless disagreement, or disagreement in general, requires incompatibility of contents. Khoo and Knobe (2018) have found compelling evidence that speakers' intuitions about disagreement and their intuitions about content compatibility diverge at least in moral cases, and taste cases, to which I will turn again for the rest of this section, are likely to yield similar results (see also Huvenes 2012, 2014; López de Sa 2015). ${ }^{11}$ The data collected by Khoo and Knobe show that speakers can take a conversation to be an instance of disagreement even if they do not take participants in it to be expressing incompatible contents. Different accounts of disagreement have been proposed that could be taken to explain this divergence in the case of taste. In particular, it has been proposed to understand disagreements about taste as metalinguistic negotiations (Plunkett and Sundell 2013), as clashes of conative attitudes (Huvenes 2012), and in terms of expectations (Björnsson 2015). In what follows, I discuss whether indexical relativism can account for disagreement understood in these different ways. After doing this, I will turn to the corresponding ways of understanding retraction.

Plunkett and Sundell (2013) have argued that the appearance of disagreement when speakers discuss about matters of taste is not to be accounted for in terms of incompatible contents, but in terms of different uses of the same word. That is, Plunkett and Sundell characterize disagreements about matters of taste as metalinguistic negotiations. If they are right, it is not a problem for indexical relativism not to yield incompatible contents for Alice's and Beth's assertions, for they can be said to be disagreeing anyway inasmuch as they use the word "tasty" in different ways.

\footnotetext{
11 Conclusions similar to the ones I will reach should follow for indicative conditionals and imperatives as well.
} 
However, it is hard to see how Alice and Beth could take themselves to be disagreeing if we understand their dispute in this way. Let us focus on Beth's point of view. When Alice utters (1) "Licorice is tasty", Beth should take her to be expressing a proposition that includes Beth's personal taste standard. This is so because Beth's standard is the one determined by the context from which Beth assesses Alice's assertion. Consider now what would happen if Beth herself uttered (1). In this case, she should take herself to be expressing a proposition that would again include her standard, as the context of assessment, and consequently the relevant standard, is the same. Thus, from Beth's point of view, Alice's utterance of (1) has the same content it would have had if it had been made by Beth. Therefore, Beth should take Alice to mean by "tasty" just what Beth herself means. In a sense, Beth has no access to the meaning that "tasty" has for Alice, so she cannot disagree with that meaning. There is no way in which she could come to realize that "tasty" means for Alice something different than it means for her, as indexical relativism precludes her from understanding Alice's utterance of (1) as meaning anything different from what she would mean by it.

Of course, from an external point of view we could see that Alice and Beth are using "tasty" in different ways, so they are having a metalinguistic disagreement. But, just like we needed disagreement in terms of incompatibility of contents to be present from both the speakers' perspective and ours, metalinguistic disagreement should be detectable from both points of view. Indexical relativism gets us incompatible contents only from the speakers' perspective and different meanings only from ours. Moreover, as Marques (2017) argues, it seems implausible that Alice and Beth attribute different meanings to "tasty". When Alice says (1) and Beth replies with (25) "No, it isn't", they are disagreeing about whether licorice is tasty, not about how best to use the word "tasty", even if that is where the conversation could lead them. Not every evaluative issue can be reduced to what words should meanthere are plenty of cases in which we are evaluating things themselves.

An alternative construal of disagreements about taste, embraced by Marques $(2014,2015)$ herself, is the one that takes them to correspond to clashes of conative attitudes (Huvenes 2012). According to this construal, we take speakers involved in disputes about taste to disagree because, in spite of their expressing compatible contents, they accept incompatible standards of personal taste. If this is all we need to declare an exchange an instance of disagreement, indexical relativism will be able to characterize Alice and Beth's as one, as their standards cannot be endorsed at the same time. Again, however, Beth would take the content of Alice's utterance of (1) to contain Beth's own standard, so there would not be two standards in opposition for her, even if there are for us. Just like happened with the meaning that "tasty" had for Alice when we understood disagreements about taste as metalinguistic negotiations, Beth has no access to Alice's personal taste standard that allows her to disagree with it. Thus, although Alice and Beth can be said to disagree from an external perspective, none of them can take herself to being disagreeing with the other.

Björnsson's (2015, pp. 173-177) account of disagreements about taste, finally, dispenses with incompatibility of contents without turning Alice and Beth's disagreement into one about the meaning of the speakers' words or a clash of conative attitudes. According to Björnsson, two claims disagree if accepting one 
would mean rejecting the other (Björnsson 2015, p. 175), where accepting that $X$ is tasty or rejecting that it is not means to expect to have a positive taste experience from $X$, and accepting that $X$ is not tasty or rejecting that it is means to expect not to have a positive taste experience from $X$ (Björnsson 2015, p. 177). If this is so, accepting (1) means to expect to have a positive taste experience from licorice, which is what it means to reject (25). Hence, Alice and Beth disagree, no matter whether the contents of their utterances are incompatible or not. Indexical relativism is thus, as far as I can see, able to account for disagreement in this sense. This is so because Björnsson's account of disagreement does not operate in terms of anything that the indexical relativist takes to be relativized. It does not rely on the propositions expressed, but neither on meanings or conative attitudes, both of which depend on a personal taste standard that is relative to each speaker. Whether Björnsson's account of disagreement is satisfactory enough to replace those operating in terms of incompatibility of contents, however, lies beyond the scope of this paper.

Just like disagreement can be understood in different ways, so can retraction. After all, we retract our previous assertions when we disagree with our past self. Thus, we could understand Alice's retraction of (1) as involving a new sense of "tasty", a standard of personal taste incompatible with the one she endorsed back when she made the utterance, or modified expectations. But the first two of these views on retraction face the same problems as the corresponding views on disagreement. If we understand retraction as resulting from metalinguistic negotiation with one's past self, on the one hand, Alice has no access to the sense in which she originally used the word "tasty". Instead, she will take "tasty" to have meant what it means for her now, as, again, from her current perspective the content she expressed through her past utterance of (1) is exactly the same she would express if she uttered the sentence now. If we understand retraction as resulting from a clash with one's previous conative attitudes, on the other hand, Alice has no access to the personal taste standard she once held-she will take it to be identical to her current one. If we understand retraction as resulting from renewed expectations, however, it will be warranted as long as Alice is aware that she expects different things from licorice now. Again, though, it remains to be seen whether an account of retraction along these lines is preferable to one in terms of incompatibility of contents.

The message to take home from this section is that the power of MacFarlane's relativism does not exclusively reside in the fact that it is a variety of relativism, but also in the fact that it is a nonindexical theory. The introduction of the context of assessment allows MacFarlane to make sense of the idea that we can retract a previous assertion because we can change our minds and, arguably, also of the idea that participants in a faultless disagreement are not at fault). But it is the nonindexical component of the theory that allows him to make sense of the ideas that faultess disagreement is a kind of disagreement and that retraction is triggered by a change of mind, whether this means a change in beliefs about taste, beliefs about meaning, or standards. An alternative would be to explain both faultless disagreement and retraction in terms of a change of expectations, as Björnsson does. As I said, however, pursuing this option lies beyond the scope of this paper. 


\section{Concluding Remarks}

Indexical relativism seems a nonstarter, even if not for the reasons pointed out by MacFarlane. However, this does not mean that nothing can be learned from trying to flesh out what it implies and why it is implausible. In particular, I hope to have contributed to a better understanding of the degree to which relativism depends on being a nonindexical theory so as not to lose what nonindexical contextualism has achieved, i.e., accounting for faultless disagreement understood as incompatibility of contents. Moreover, it is because of its indexical character that indexical relativism does not seem capable of accounting for faultless disagreements understood as metalinguistic negotiations or clashes of attitudes, or for most of the ways in which we might understand retraction, which is precisely the kind of phenomenon that motivated the introduction of nonindexical relativism.

Acknowledgments The author would like to thank Manuel Almagro, María José Frápolli, Claudia Picazo, Neftalí Villanueva, and two anonymous reviewers for Philosophia, as well as the audience at PhiLang 2021, for their helpful comments and suggestions.

Funding Funding for open access charge: Universidad de Granada/CBUA. This paper has been funded by the Spanish Ministry of Universities under the grant FPU14/00485, by the Spanish Ministry of Science and Innovation under the research projects "Contemporary Expressivisms and the Indispensability of Normative Vocabulary: Scope and Limits of the Expressivist Hypothesis" (FFI2016-80088-P) and "Disagreement in Attitudes: Normativity, Affective Polarization and Disagreement" (PID2019-109764RBI00), by the Regional Government of Andalusia under the research projects "Public Disagreements, Affective Polarization and Immigration in Andalusia" (B-HUM-459-UGR18) and "The Inferential Identification of Propositions: A Reconsideration of Classical Dichotomies in Metaphysics, Semantics and Pragmatics" (P18-FR-2907), and by the University of Granada under a "Contrato Puente" fellowship and the excellence unit FiloLab-UGR (UCE.PPP2017.04).

Open Access This article is licensed under a Creative Commons Attribution 4.0 International License, which permits use, sharing, adaptation, distribution and reproduction in any medium or format, as long as you give appropriate credit to the original author(s) and the source, provide a link to the Creative Commons licence, and indicate if changes were made. The images or other third party material in this article are included in the article's Creative Commons licence, unless indicated otherwise in a credit line to the material. If material is not included in the article's Creative Commons licence and your intended use is not permitted by statutory regulation or exceeds the permitted use, you will need to obtain permission directly from the copyright holder. To view a copy of this licence, visit http://creativecommons.org/licen ses/by/4.0/.

\section{References}

Björnsson, G. (2015). Disagreement, correctness, and the evidence for metaethical absolutism. Oxford Studies in Metaethics, 4, 160-187.

Braun, D., \& Sider, T. (2007). Vague, so untrue. Noûs, 41(2), 133-156.

Buchanan, R. (2010). A puzzle about meaning and communication. Noûs, 44(2), 340-371.

Cappelen, H. (2008a). Content relativism and semantic blindness. In M. García-Carpintero \& M. Kölbel (Eds.), Relative truth (pp. 265-286). Oxford University Press.

Cappelen, H. (2008b). The creative interpreter: Content relativism and assertion. Philosophical Perspectives, 22, 23-46. 
Cappelen, H., \& Hawthorne, J. (2009). Relativism and monadic truth. Oxford University Press.

Cappelen, H., \& Lepore, E. (1997). On an alleged connection between indirect speech and the theory of meaning. Mind and Language, 12(3/4), 278-296.

Cappelen, H., \& Lepore, E. (2003). Context shifting arguments. Philosophical Perspectives, 17, $25-50$.

Cappelen, H., \& Lepore, E. (2004). Insensitive semantics: A defense of minimalism and speech act pluralism. Blackwell.

Chrisman, M. (2007). From epistemic contextualism to epistemic expressivism. Philosophical Studies, 135(2), 225-254.

Clapp, L., \& Lavalle Terrón, A. (2019). Multipropositionalism and necessary a posteriori identity statements. Pacific Philosophical Quarterly, 100(4), 902-934.

Davidson, D. (1968). On saying that. Synthese, 19(1/2), 130-146.

Egan, A. (2009). Billboards, bombs and shotgun weddings. Synthese, 166(2), 251-279.

Egan, A. (2011). Relativism about epistemic modals. In S. D. Hales (Ed.), A companion to relativism (pp. 219-241). Wiley-Blackwell.

Egan, A., Hawthorne, J., \& Weatherson, B. (2005). Epistemic modals in context. In G. Preyer \& G. Peter (Eds.), Contextualism in philosophy: Knowledge, meaning, and truth (pp. 131-168). Oxford University Press.

Field, H. (2009). Epistemology without metaphysics. Philosophical Studies, 143(2), 249-290.

Huvenes, T. T. (2012). Varieties of disagreement and predicates of personal taste. Australasian Journal of Philosophy, 90(1), 167-181.

Huvenes, T. T. (2014). Disagreement without error. Erkenntnis, 79(S1), 143-154.

Kaplan, D. (1977/1989). Demonstratives: An essay on the semantics, logic, metaphysics, and epistemology of demonstratives and other indexicals. In J. Almog, J. Perry, \& H. Wettstein (Eds.), Themes from Kaplan (pp. 481-563). Oxford University Press.

Khoo, J., \& Knobe, J. (2018). Moral disagreement and moral semantics. Noûs, 52(1), 109-143.

King, J. (2014). The metasemantics of contextual sensitivity. In A. Burgess \& B. Sherman (Eds.), Metasemantics: New essays on the foundations of meaning (pp. 97-118). Oxford University Press.

Kölbel, M. (2004). Faultless disagreement. Proceedings of the Aristotelian Society, 104(1), 53-73.

López de Sa, D. (2011). The many relativisms: Index, context, and beyond. In S. D. Hales (Ed.), A companion to relativism (pp. 102-117). Wiley-Blackwell.

López de Sa, D. (2015). Expressing disagreement. Erkenntnis, 80(1), 153-165.

MacFarlane, J. (2005). Making sense of relative truth. Proceedings of the Aristotelian Society, 105(1), 305-323.

MacFarlane, J. (2014). Assessment sensitivity: Relative truth and its applications. Oxford University Press.

Marques, T. (2014). Doxastic disagreement. Erkenntnis, 79(S1), 121-142.

Marques, T. (2015). Disagreeing in context. Frontiers in Psychology, 6, 257.

Marques, T. (2017). What metalinguistic negotiations can't do. Phenomenology and Mind, 12, 40-48.

Pérez-Navarro, E. (2021). No matter who: What makes one a relativist? Theoria: An International Journal for Theory, History and Foundations of Science, 36(2), 231-242.

Percival, P. (1994). Absolute truth. Proceedings of the Aristotelian Society, 94(1), 189-213.

Perry, J. (2001). Reference and reflexivity. CSLI Publications.

Pietroski, P. M. (1996). Fregean innocence. Mind and Language, 11(4), 338-370.

Plunkett, D., \& Sundell, T. (2013). Disagreement and the semantics of normative and evaluative terms. Philosophers' Imprint, 13(23), 1-37.

Predelli, S. (1996). Never put off until tomorrow what you can do today. Analysis, 56(2), 85-91.

Predelli, S. (1998a). I am not here now. Analysis, 58(2), 107-115.

Predelli, S. (1998b). Utterance, interpretation and the logic of indexicals. Mind and Language, 13(3), 404-414.

Schlenker, P. (2004). Context of thought and context of use: A note on free indirect discourse and the historical present. Mind and Language, 19(3), 279-304.

Sidelle, A. (1991). The answering machine paradox. Canadian Journal of Philosophy, 21(4), 525-539.

Stalnaker, R. (1978). Assertion. In P. Cole (Ed.), Pragmatics (pp. 315-332). New York Academy Press.

von Fintel, K., \& Gillies, A. S. (2008). CIA leaks. The Philosophical Review, 117(1), 77-98.

von Fintel, K., \& Gillies, A. S. (2011). 'Might' made right. In A. Egan \& B. Weatherson (Eds.), Epistemic modality (pp. 108-130). Oxford University Press. 
Weatherson, B. (2009). Conditionals and indexical relativism. Synthese, 166(2), 333-357.

Publisher's Note Springer Nature remains neutral with regard to jurisdictional claims in published maps and institutional affiliations. 